\title{
Resistance to Puccinia coronata f. sp. avenae in Avena magna, A. murphyi, and $A$. insularis
}

Sylwia Sowa, Edyta Paczos-Grzęda, Aneta Koroluk, Sylwia Okoń, Agnieszka Ostrowska, Tomasz Ociepa, Maria Chrząstek, and Krzysztof Kowalczyk, Institute of Plant Genetics, Breeding and Biotechnology, University of Life Sciences in Lublin, Lublin, Poland

\begin{abstract}
Sowa, S., Paczos-Grzęda, E., Koroluk, A., Okoń, S., Ostrowska, A., Ociepa, T., Chrząstek, M., and Kowalczyk, K. 2016. Resistance to Puccinia coronata f. sp. avenae in Avena magna, A. murphyi, and A. insularis. Plant Dis. 100:1184-1191.

Wild oat tetraploids of the section Pachycarpa have already been proven to be a rich source of useful genes but have largely been unexploited for Puccinia coronata resistance. In this study, accessions of Avena magna, A. murphyi, and A. insularis gathered from European and North American gene banks were evaluated at the seedling stage for crown rust reaction using the host-pathogen test and six highly diverse and virulent $P$. coronata isolates. Of the 92 Avena accessions analyzed, 58.7\% were resistant to at least one crown rust race. In all, $37 \%$ of the tested accessions reacted

nonuniformly, which indicated their heterogeneity. The highest level of resistance was observed in three of the accessions, one of which was verified by flow cytometry as being hexaploid and two of which were verified as being tetraploids. The infection profiles of 19 accessions corresponded to resistance determined by the genes $P c 14, P c 39, P c 40, P c 48, P c 50, P c 54$ $P c 55, P c 61, P c 67, P c 68, P c 97, P c 101$, or Pc104. The patterns of infection of the remaining resistant $A$. magna and $A$. murphyi accessions allowed us to postulate the presence of potentially novel crown rust resistance genes.
\end{abstract}

Oat is a valuable crop that has accompanied human kind for thousands of years. In terms of growing conditions, it is a particularly undemanding plant but, in comparison with other cereals, it has a rather low yield per hectare (Budzyński and Szempliński 2003). The health of the plant has a significant influence on the harvest. Cultivated oat is affected by a number of fungal diseases, among which crown rust caused by Puccinia coronata f. sp. avenae is the most widespread and harmful (Simons 1985). Crown rust reduces not only the yield but also the quality of the grain, and increases lodging (Fleischmann and McKenzie 1968; Martens et al. 1972; Simons 1985). The most effective biological control of this disease is genetic resistance (Harder and Haber 1992). Growing resistant varieties is a highly economical and environmentally friendly alternative to chemical control. Therefore, the use of race-specific genes $(P c$ genes, in the case of crown rust) has been one of the major objectives of plant breeding programs. Crown rust resistance in oat is usually conferred by single, dominant genes; however, recessive or incompletely dominant genes, as well as genes that inhibit resistance genes, have been also identified (Simons 1979; Wise et al. 1996). Resistance can be the effect of interactions of two or more genes (Harder and McKenzie 1984; Simons et al. 1979; Wong et al. 1983) Moreover, these genes are known to exist in clusters in the genome, in groups that are either tightly linked or allelic; for example, $P c 38$ is clustered with $P c 62$ and Pc63 (Harder and McKenzie 1980), Pc39 with Pc55 (Kiehn et al. 1976), or Pc35 with Pc54 (Martens et al. 1980).

Studies characterizing the genetics of crown rust resistance in Avena spp. have been carried out since the 1920s (Gnanesh et al. 2013). Initially, $P c$ genes already present in cultivated hexaploid oat were studied and deployed (Martens and Dyck 1989). With the spread of resistant cultivars and the use of long-term monoculture cultivation practices, selection pressure on rust populations led to the emergence of new races, which overcame this resistance. By the late 1950s, the known sources of resistance rapidly became ineffective (Chong et al. 2000); thus, it was necessary to search for new resistance sources among wild oat species.

Corresponding author: E. Paczos-Grzęda; E-mail: edyta.paczos@up.lublin.pl Accepted for publication 4 January 2016.

http://dx.doi.org/10.1094/PDIS-06-15-0671-RE

(C) 2016 The American Phytopathological Society
Effective resistance breeding work depends on the successful transfer of valuable genes from wild species to cultivated forms. Based on the gene pool classification system, all Avena spp. are grouped into three gene pools (Harlan and de Wet 1971). The primary one contains all of the hexaploid species of wild and cultivated oat. They cross relatively easily and produce fertile progeny. The secondary gene pool includes tetraploid species of the section Pachycarpa (Avena magna Murphy et Terrell [synonym: A. maroccana Gdgr.], A. murphyi Ladiz., and A. insularis Ladiz.) that cross with cultivated oat directly but give partially sterile progeny, which may produce a small number of seed through backcrossing to the hexaploid parent. The tertiary gene pool contains all of the diploid Avena spp., as well as the remaining tetraploids (A. barbata Pott. ex Link., A. vaviloviana Mordv., A. abysinnica Hochst., A. agadiriana Baum et Fedak, and A. macrostachya Bal. ex Coss. et Dur.). Introgression of resistance from diploid and tetraploid Avena spp. into cultivated oat is possible but difficult, due to the difference in ploidy levels, the lack of chromosome homology, and special technical requirements, such as having to use in vitro techniques (Jellen and Leggett 2006).

The first success in the transfer of crown rust resistance genes between species was accomplished using the wild hexaploid A. sterilis L. (Segal et al. 1980; Simons 1985). Accessions of this species, derived from the Mediterranean and adjacent regions (Loskutov and Rines 2011), have been the richest source of resistance genes, with over $40 P c$ genes described. However, after the resistance genes from $A$. sterilis were broadly deployed in new oat cultivars, the corresponding virulence in the $P$. coronata population continued to evolve. This led to the search for new, effective resistance genes from related species of lower ploidy levels (Gnanesh et al. 2013). The diploid black oat $A$. strigosa Schreb. has been used in breeding programs; however, despite the large number of resistance genes identified within this species, only $P c 23$ and $P c 94$ have been incorporated into a stable $A$. sativa $\mathrm{L}$. background, due to barriers in the integration of genes (Aung et al. 1996; Dyck and Zillinsky 1963). As an example, the $P c 94$ gene originating from A. strigosa accession RL1697 was introduced into the recently released 'Leggett' and 'Stride' (Mitchell Fetch et al. 2007, 2013). In addition, the wild tetraploid accession A. magna CI 8330 was the source of $P c 91$, the extremely effective crown rust resistance gene found in the oat ' $\mathrm{HiFi}$ '. $P c 91$ is the only gene that has been successfully introduced into cultivated oat from a wild tetraploid (Rothman 1984).

Many useful features of particular interest in the context of oat breeding have been found among the tetraploids of the secondary 
gene pool; for example, traits determining the high productivity and quality of the grain (Ladizinsky 1988), adaptability to different climatic and soil conditions, and highly desirable resistance to powdery mildew as well as resistance to stem rust, Barley yellow dwarf virus, and Septoria leaf blight (Gnanesh et al. 2013). However, tetraploids of the secondary gene pool still remain unexploited as a source of resistance to crown rust. It should be possible to introgress crown rust resistance from A. magna, A. murphyi, and A. insularis into cultivated oat, as discussed by Aung et al. (1996), Karow et al. (1987), and Sadanaga and Simon (1960).

Searching for new sources of crown rust resistance genes in the tetraploids is a key objective in plant protection. Previous studies that focused on the screening of wild oat accessions were limited in terms of sources of the tested materials as well as the species analyzed (Cabral and Park 2014; Carson 2009a, 2010; Tan and Carson 2013). The current work complements existing data and reveals the spectrum of potential new resistance genes or alleles present in the wild tetraploids and previously misidentified Avena hexaploid accessions gathered from a number of gene banks.

\section{Materials and Methods}

The examined plant material consisted of 92 wild oat accessions received during the years 2006 to 2009 from the following gene banks: Genetic Resources Unit, Institute of Biological, Environmental and Rural Sciences (IBERS), Aberystwyth, Wales; National Centre For Plant Genetic Resources, The Plant Breeding and Acclimatization Institute (IHAR), NRI, Radzików, Poland; Leibniz Institute of Plant Genetics and Crop Plant Research, Gatersleben, Germany; National Small Grains Collection (NSGC), Aberdeen, ID; Plant Gene Resources of Canada, Agriculture and Agri-Food Canada, Saskatoon, Canada; N. I. Vavilov Institute of Plant Genetic Resources, St. Petersburg, Russia; and Department of Plant and Wildlife Sciences, Brigham Young University, Provo, UT. Of these, 66 accessions were classified as A. magna, 22 were assigned to $A$. murphyi, and 4 to $A$. insularis (Table 1). Additionally, the hexaploid line 'Amagalon' was used as a representative of $P c 91-$ the only resistance gene deployed in cultivated oat that was derived from a tetraploid species.

All A. magna accessions came originally from Morocco, while the A. murphyi accessions came mostly from Spain but also from Morocco. Accessions belonging to the species A. insularis originated in Sicily and Tunisia. According to the European Avena Database (http://eadb.jki.bund.de/eadb/), A. magna accession AVE 2849 is a putative duplicate of CN 23059, while A. magna VIR 1896 and AVE 2852 and A. murphyi AVE 2846 are presumed to be duplicates of Cc 7245, Cc 7073, and CN 21989, respectively. Moreover, A. magna Cc 7183A and Cc 7183B were selected based on seed morphological differences within one $\mathrm{Cc} 7183$ accession.

For ploidy estimation, leaves of three different 12-day-old seedlings of each genotype were collected. The plant material was prepared for flow cytometry according to Galbraith et al. (1983). Young leaves were chopped with a sharp razor blade in a plastic petri dish with Galbraith's nuclei isolation buffer supplemented with 4',6daimidino-2-phenylindole ( $2 \mathrm{mg} / \mathrm{ml})$. After chopping, the suspension was passed through a 50-mm mesh nylon filter. Each sample was analyzed directly after preparation using a Partec CCA flow cytometer (Munster, Germany). Analyses were replicated three times for each sample. A. sativa 'Bingo' $(2 \mathrm{n}=6 \mathrm{x}=6 \mathrm{C})$ was used as an internal standard.

The crown rust resistance tests were conducted using six $P$. coronata f. sp. avenae isolates (A to F) with the defined virulences specified in Table 2. These were the most virulent and diverse pathogens selected from a collection of 100 single-pustule isolates obtained from $P$. coronata populations collected in the years 2010 to 2014 from oat flag leaves from random farm fields and field plots of Polish breeding companies. Leaf fragments with single uredinia were taken from infected plants at different locations. To increase single-uredinia pustules, the susceptible oat 'Marvelous' was inoculated with urediniospores obtained from the leaves following the host-pathogen test methodology of Hsam et al. (1997). Ten-day-old, 3-cm-long fragments of Marvelous leaves were placed into petri dishes filled with agar $(0.6 \%)$ containing benzimidazole $(3.4 \mathrm{mM})$. The plates with leaves were inoculated in a settling tower by spreading uredinospores onto the plant material at a density of 500 to 700 spores $/ \mathrm{cm}^{2}$. After inoculation, plates were incubated for $20 \mathrm{~h}$ in the dark at $100 \%$ humidity and temperature of $18^{\circ} \mathrm{C}$, and thereafter for 10 days in a growth chamber at $18^{\circ} \mathrm{C}$ under a 14-h photoperiod, with light intensity reaching $4 \mathrm{kLx}$ and $70 \%$ humidity.

To define the virulence of the multiplied single-pustule isolates, each of them was examined on a set of 35 differential lines of oat with single resistance genes as well as the control cultivar (Marvelous). The differential near-isogenic lines Pc14, Pc36, Pc51, Pc52, Pc70, and $P c 71$ were developed at Iowa State University and the lines Pc35, Pc38, Pc39, Pc40, Pc45, Pc46, Pc48, Pc50, Pc54, Pc55, Pc56, Pc57, Pc62, Pc63, Pc64, Pc67, Pc68, Pc91, Pc94, Pc96, Pc97, Pc98, $P c 101, P c 103-1$, and Pc104 were developed at the Cereal Research Centre AAFC, Winnipeg, Canada (Carson 2011; Chong et al. 2011; Menzies et al. 2015). Pc58, Pc59, Pc60, and Pc61 were represented by 'TAM-O-301', 'TAM-O-312', 'Coker227', and 'Coker234', respectively (Simons 1978). Seed of the 35 reference lines were seeded onto plug trays filled with a universal substrate mixed with peat and allowed to germinate. Three replications were performed using the host-pathogen test methodology cited above. Assessment of leaf infection was performed after 10 days of incubation in a growth chamber. Lines with no visible reaction or the presence of only small colonies surrounded by necrotic and chlorotic changes were considered to be resistant, whereas lines with medium-sized or large colonies surrounded by chlorotic changes were considered to be susceptible. The virulence of each isolate was assessed on the basis of the number of infected lines. The dried spores from each isolate were stored in 1.5-ml microfuge tubes at $-70^{\circ} \mathrm{C}$ for further use.

Six selected $P$. coronata isolates (A to F) were used to carry out the host-pathogen test to assess the susceptibility of the studied wild oat genotypes. Before inoculation, crown rust urediniospores were heat shocked for $4 \mathrm{~min}$ at $42^{\circ} \mathrm{C}$ and multiplied on susceptible Marvelous using the host-pathogen test procedure. Wild oat grains were seeded onto plug trays filled with a universal substrate mixed with peat and allowed to germinate. Young seedling leaf fragments $(3 \mathrm{~cm}$ long) were collected after 10 days and placed into 12-well culture plates filled with agar. Three leaf fragments, each from a different seedling of one accession, were placed on the plate. Leaves of susceptible Marvelous were used as a control. The plates with leaves were inoculated with the selected isolates according to the methodology cited above.

Assessment of leaf infection was performed after 10 days using the numeric 0-to-4 scale of Murphy (1935). These scores were converted into qualitative scale of $\mathrm{S}, \mathrm{MS}, \mathrm{MR}, \mathrm{R}$, and HR, where reaction phenotypes were assigned as $4=$ susceptible (S), large to moderately large pustules with little or no chlorosis; $3=$ moderately susceptible (MS), moderately large pustules surrounded by extensive chlorosis; $2=$ moderately resistant (MR), small pustule surrounded by chlorosis; $1=$ resistant $(\mathrm{R})$, chlorotic or necrotic flecking; and $0=$ highly resistant $(\mathrm{HR})$, no visible reaction (Carson 2009a). Phenotypes described as S and MS were considered to be susceptible, while others were regarded as being resistant. The infection profiles (IP) of the wild accessions determined for six tested isolates were then compared with the IP of the differential lines.

\section{Results}

Flow cytometry analysis was conducted because of doubts concerning the ploidy level of some oat material that arose after the

Table 1. Number of wild oat species accessions tested for crown rust resistance

\begin{tabular}{llc}
\hline Species & Ploidy level & Number of accessions \\
\hline Avena magna & $2 \mathrm{n}=4 \mathrm{x}=28$ & 66 \\
A. murphyi & $2 \mathrm{n}=4 \mathrm{x}=28$ & 22 \\
A. insularis & $2 \mathrm{n}=4 \mathrm{x}=28$ & 4 \\
\hline
\end{tabular}


preliminary morphological analysis of the seed and plants to be studied. Among the 92 Avena genotypes thought to be tetraploids, $7 \mathrm{pu}-$ tative A. magna accessions had a level of ploidy different than expected (Table 3 ). These seven misclassified A. magna accessions seem to represent $A$. sterilis, not only because of their hexaploid number of chromosomes but also because of their phenotypic similarity to A. magna tetraploids. A. magna is considered to be the progenitor of A. sterilis and has strong morphological resemblance to this hexaploid species.

The IP of the 35 differential near-isogenic lines inoculated with the full set of 100 isolates of $P$. coronata were analyzed in terms of susceptibility and diversity. None of the isolates broke the resistance of lines $P c 52, P c 59, P c 60, P c 63, P c 71$, or Pc91. Pathotype A was found to be the most aggressive, infecting 25 of 35 tested lines. Five other isolates, which broke the resistance of 18 (pathotype B), 14 (pathotypes C and D), 11 (pathotype E), and 10 (pathotype F) differential lines (Table 2), were selected for their diversity to help differentiate as many $P c$ resistance genes as possible.

All of the 92 wild Avena accessions were evaluated for crown rust reaction using the subset of six $P$. coronata isolates. The $P$. coronata $\mathrm{f}$. sp. avenae response ranged from $\mathrm{S}$ to HR (Table 4). Resistance to at least one $P$. coronata isolate was observed within 54 of the 92 Avena accessions (58.7\%). In all, 58 accessions (41 A. magna, 9 A. murphyi, 3 A. insularis, and 5 verified hexaploids) displayed a repeatable and homogeneous reaction to $P$. coronata. Variation in the susceptibility response showed that $37 \%$ of the tested accessions are heterogeneous. As many as 30 of 59 A. magna accessions (50.8\%) had genotypes resistant to at least one isolate of $P$. coronata. Cc 7237 and Cc 7241 showed resistance to five of the six crown rust pathotypes used for the tests: the first one was infected only by isolate $\mathrm{C}$ and the second only by $\mathrm{E}$. The infection patterns of the other genotypes varied. Three of them showed resistance to four $P$. coronata f. sp. avenae isolates, nine were resistant to three, and four to two. Genotype CI 8330, which served as a donor of the $P c 91$ gene, showed no resistance, while Amagalon, the hexaploid line obtained by crossing A. longiglumis with A. magna CI 8330, was fully resistant to all isolates used. A. murphyi genotypes showed a significantly higher degree of crown rust resistance compared with A. magna. Resistance to P. coronata was observed in $17(77.3 \%)$ of the 22 A. murphyi accessions evaluated. Accessions Cc 7190 and PI 657600 were characterized by the total lack of infection symptoms. Three accessions-Cc 7178, Cc 7181, and Cc 7185-showed resistance to five of the six isolates used in the tests whereas, in Cc 7180, Cc 7188, Cc 7189, and Cc 7240, resistance to four crown rust pathotypes was observed, ranging from HR to MR. Resistance among the other accessions infected by three or more $P$. coronata $\mathrm{f}$. sp. avenae isolates was predominantly MR. Of the tested genotypes of A. insularis, only the 2067 VIR genotype showed resistance, and that was to isolate $\mathrm{D}$.

Two of the putative A. magna duplicate pairs, AVE 2849 and CN 23059 as well as VIR 1896 and Cc 7245, showed homogeneous S reactions to the isolates used in the tests. Another two presumably duplicated pairs, A. magna Cc 7073 and AVE 2852, as well as A. murphyi AVE 2849 and CN 21989, responded extremely diversely, giving fully $\mathrm{S}$ to $\mathrm{HR}$ reactions. Differentiated reactions also were observed in the two specimens of the accession Cc 7183 that had been selected based on seed morphology.

The highest level of resistance was observed in accessions whose ploidy level was verified by flow cytometry as being hexaploid. Accessions PI 657615, PI 657616, and PI 657618 exhibited full resistance, rated from moderate to high. Cc 7247 and Cc 7243 were resistant to four of six tested isolates: $\mathrm{C}, \mathrm{D}, \mathrm{E}$, and F and A, B, D, and $\mathrm{E}$, respectively.

The virulence levels of the $P$. coronata isolates used were similar. The most aggressive, inducing an $\mathrm{S}$ response in about $85 \%$ of the evaluated Avena genotypes, were the isolates A, B, E, and F. Infections caused by pathotypes $\mathrm{C}$ and $\mathrm{D}$ were at levels of 75 and $66 \%$, respectively. Pathotype A was found to be the most virulent toward the genotypes of A. magna, because it infected 57 of 59 accessions. Isolate D showed the weakest level of virulence: 23 accessions of A. magna were resistant to it. These observations differed from the response to infection of $A$. murphyi, where the most virulent proved to be the B pathotype, infecting as many as 21 of the 22 genotypes. The lowest rate of infection among A. murphyi genotypes was seen using the A and D isolates and, particularly $\mathrm{C}$, because it overcame the resistance of only 14 accessions.

The IP of individual accessions determined for six tested isolates were also analyzed. Of the 92 genotypes studied, 19 had IP corresponding to the presence of known resistance genes: $P c 39(n=1)$, Pc40 $(n=1), \operatorname{Pc50}(n=2), \operatorname{Pc} 54(n=7), \operatorname{Pc} 61(n=1), \operatorname{Pc} 67(n=$ 1), Pc104 $(n=1), P c 48$ or Pc55 $(n=1), P c 68(n=1)$, and Pc14, $P c 97$, or Pc101 $(n=3)$ (Table 4). The susceptibility patterns in the A. murphyi accessions suggested the possible presence of $P c 40(\mathrm{Cc}$ 7179), Pc50 (Cc 7181), Pc61 (Cc 7178), Pc67 (52220), Pc104 (Cc 7185), and Pc14, Pc97, or Pc101 (Cc 7180, Cc 7240, and hexaploid Cc 7247). Further, in A. magna, the presence of the following genes can be postulated: $P c 39$ (Cc 7183A), Pc50 (Cc 7237), Pc48 or Pc55 (AVE 2784), Pc54 (CN 23040, CN 23044, Cc 7069, 5222 IHAR, CN 23043, and CN 23114), and Pc68 (Cc 7241). Gene Pc54 may also

Table 3. Ploidy level of Avena accessions originally described as being tetraploid Avena magna, then reassessed by means of flow cytometry

\begin{tabular}{lccc}
\hline Accession & Gene bank $^{\mathbf{a}}$ & Expected ploidy lavel & Obtained ploidy lavel \\
\hline Cc 7243 & IBERS & Tetraploid & Hexaploid \\
Cc 7244 & IBERS & Tetraploid & Hexaploid \\
Cc 7247 & IBERS & Tetraploid & Hexaploid \\
PI 657271 & NSGC & Tetraploid & Hexaploid \\
PI 657615 & NSGC & Tetraploid & Hexaploid \\
PI 657616 & NSGC & Tetraploid & Hexaploid \\
PI 657618 & NSGC & Tetraploid & Hexaploid \\
\hline
\end{tabular}

${ }^{\text {a }}$ IBERS = Genetic Resources Unit, Institute of Biological, Environmental and Rural Sciences, Aberystwyth, Wales and NSGC $=$ National Small Grains Collection, Aberdeen, ID.

${ }^{\mathrm{b}}$ Accession was verified in database in 2011 as being A. sterilis.

Table 2. Virulence spectrum of Puccinia coronata var. avenae pathotypes used for testing resistance of wild oat accessions

\begin{tabular}{lccc}
\hline Isolate & Phenotype code & \multicolumn{1}{c}{ Virulence to standard differentials $^{\mathbf{a}}$} & \multicolumn{1}{c}{ Virulence to supplemental differentials $^{\mathbf{b}}$} \\
\hline $\mathrm{A}$ & $\mathrm{SSNT}$ & $P c 38, P c 39, P c 48, P c 40, P c 45, P c 46, P c 51, P c 58, P c 54$, & $P c 14, P c 35, P c 36, P c 55, P c 57, P c 61, P c 67, P c 94$, \\
& & $P c 56, P c 62, P c 64$ & $P c 96, P c 97, P c 98, P c 101, P c 103-1$ \\
$\mathrm{~B}$ & $\mathrm{DSLP}$ & $P c 48, P c 40, P c 45, P c 46, P c 51, P c 54, P c 62, P c 64$ & $P c 14, P c 55, P c 57, P c 67, P c 96, P c 97, P c 98, P c 101$, \\
& & $P c 103-1, P c 104$ \\
$\mathrm{C}$ & $\mathrm{SKDR}$ & $P c 38, P c 39, P c 48, P c 45, P c 46, P c 50, P c 58, P c 54$, & $P c 36, P c 55, P c 94, P c 96$ \\
& & $P c 56, P c 64$ & \\
$\mathrm{D}$ & $\mathrm{JPDK}$ & $P c 39, P c 48, P c 40, P c 46, P c 58, P c 56, P c 62, P c 64$ & $P c 35, P c 55, P c 57, P c 67, P c 70, P c 98$ \\
$\mathrm{E}$ & $\mathrm{RSLN}$ & $P c 38, P c 48, P c 46, P c 40, P c 45, P c 46, P c 51, P c 54, P c 62$ & $P c 36, P c 103-1$ \\
$\mathrm{~F}$ & $\mathrm{NDDS}$ & & $P c 36, P c 55, P c 67$ \\
\hline
\end{tabular}

a As defined by Chong et al. (2000).

b As defined by Chong et al. (2011). 
be present in A. insularis 2067 VIR. Moreover, five previously discussed genotypes-three hexaploids misclassified as A. magna (PI 657615, PI 657616, and PI 657618) and two A. murphyi accessions (Cc 7190 and PI 657600) — were not infected by any of the isolates used. Identical, absolute resistance was observed within differential lines carrying the genes $P c 52, P c 59, P c 60, P c 63$, $P c 71$, and $P c 91$.

In turn, 30 accessions had IP indicating the presence of unknown genes. These genotypes were assigned to 19 groups, each comprising accessions with a similar IP. Identified resistance against one to all of the six P. coronata f. sp. avenae pathotypes could be the effect of new genes.

\section{Discussion}

The main objective of this study was to gather all available accessions of A. magna, A. murphyi, and A. insularis and scan them for the presence of effective $P c$ genes. Plant seed received during the years 2006 to 2009 from European and North American gene banks as tetraploids served as the material for morphological observations and crosses, as well as the current study. The A. sterilis-like phenotypes of some accessions led to doubts concerning the ploidy level of these materials; thus, all accessions were analyzed by flow cytometry. Among the 92 presumably tetraploid genotypes ( 28 chromosomes, $4 \mathrm{x}$ ), 7 had different ploidy levels (42 chromosomes, $6 x$ ) than expected. Nevertheless, host-pathogen tests were carried out on all accessions collected, which resulted in finding additional effective and easy-tointroduce (to hexaploid oat cultivars) resistance genes. Accessions Cc 7243, Cc 7244, and Cc 7247 (assigned by the Genetic Resources Unit, IBERS as being A. magna) and PI 657615, PI 657616, PI 657618, and PI 657271 (provided by the NSGC) and also assigned as being A. magna, turned out to be hexaploids. After rechecking, we noticed that the last one (PI 657271) had already been described as A. sterilis. Even if the collected genotypes were not tetraploids, they were brought from the same regions of Morocco and Spain as the tetraploids and could have undergone the same effective selection pressure as $\mathrm{Cl} 8330$, the donor of the highly effective gene $P c 91$.

To date, over $100 P c$ alleles have been described (Chong et al. 2011; Gnanesh et al. 2013) and most of these resistance genes were derived from accessions of wild hexaploids, mainly A. sterilis, collected in Israel and other Mediterranean countries during the 1960s and early 1970s (Simons 1978). Because most of the known hexaploid oat germplasm has already been utilized as a source of rust resistance, the search has turned to species with lower ploidy levels. Many $P c$ genes have been found in diploid A. strigosa; however, only two of them have been incorporated into stable $A$. sativa backgrounds due to the barriers arising from ploidy level differences (Aung et al. 1996; Dyck and Zillinsky 1963). Thus far, the screening of wild accessions has confirmed crown rust resistance in the seedling and adult plant stages of $A$. barbata (Cabral and Park 2014; Cabral et al. 2011; Carson 2009a, 2010). Moreover, recent studies identified resistant genotypes in other diploid species (A. atlantica Baum et Fedak, A. damascene Rajhathy et Baum, A. hirtula Lag., A. longiglumis Dur., and A. wiestii Steud), as well as the tetraploid A. agadiriana Baum et Fedak (Tan and Carson 2013). Such discoveries may hold a promise for breeding programs in the future but introgression of resistance from these sources is difficult, because the aforementioned Avena spp. belong to the tertiary gene pool. Therefore, it seemed reasonable to screen the secondary gene pool of the genus Avena, which encompasses species more amenable to crossing with A. sativa. Recently, the successful introduction of the extremely effective and potent $P c 91$ gene from tetraploid $A$. magna into $\mathrm{HiFi}$ oat was carried out via the synthetic hexaploid Amagalon, created by crossing the A. magna line with A. longiglumis Durrit. (McMullen et al. 2005; Rooney et al. 1994). However, virulence to this gene has already been recorded in the United States (Carson 2009b), Canada (Chong et al. 2008; McCartney et al. 2011; Menzies et al. 2015), and Australia (Park 2013).

Tan and Carson (2013), in a study involving 38 A. murphyi and 40 A. magna accessions from NSGC, identified 29 (76.3\%) and $19(47.5 \%)$ resistant genotypes, respectively. The present study examined only six of the genotypes analyzed by Tan and Carson (2013) but the results obtained confirmed some of the previous findings. For example, A. murphyi PI 657600 demonstrated a wide spectrum of resistance. This accession showed a diverse, heterogeneous infection pattern ranging from $\mathrm{S}$ to $\mathrm{HR}$ in the seedling stage. Furthermore, moderate resistance was detected in A. murphyi PI 657606. Similarly, the response of the accessions PI 657288, PI 657615, PI 657616, and PI 657618 also resembled the observations of Tan and Carson (2013). The first one, A. magna, was fully susceptible, whereas the three others, confirmed as hexaploids by flow cytometry, displayed nearly completely repeatable resistance to all six isolates used in this study, as well as to the highly diverse bulk inoculum applied in the previous work by Tan and Carson (2013). Moreover, the authors cited above observed the presence of adult plant resistance in these accessions, which makes them significantly more valuable.

The six diverse, highly virulent $P$. coronata isolates used in this study allowed us to detect a broad spectrum of resistance in the tested genotypes. Of the 85 lines validated as being tetraploid wild oat accessions, $55.3 \%$ displayed resistance to at least one isolate. Resistance was observed in $30 \mathrm{~A}$. magna $(50.8 \%)$ and $17 \mathrm{~A}$. murphyi $(77.3 \%)$ accessions. The ratio of resistant to infected genotypes closely corresponded to the results of Tan and Carson (2013) published earlier. This confirms the large amount of untapped genetic potential among these species. It should be emphasized that $37 \%$ of the tested tetraploids showed a heterogeneous, diverse reaction, even those which, according to the European Avena Database (http:// eadb.jki.bund.de/eadb/), were putative duplicates. Equally diverse reactions were observed in the studies of other authors (Cabral and Park 2014; Carson 2009a, 2010; Tan and Carson 2013), which increases the likelihood of finding new, more effective crown rust resistance genes.

The greatest challenge in interspecific crosses is to overcome genetic barriers to the transfer and efficient use of valuable genes. Successful introgression of genes from diploids or tetraploids from the tertiary gene pool to hexaploid species often requires special techniques and is rather daunting, due to the lack of chromosome homology (Aung et al. 1996; Karow et al. 1987; Sadanaga and Simon 1960). Resistance genes from the wild tetraploids found in this study should be relatively easy to transfer into the $A$. sativa background, as confirmed by the example of the transfer of $P c 91$ from A. magna (McMullen et al. 2005; Rooney et al. 1994). However, another obstacle that can arise during interspecific trait transfer, and which can occur across all levels of ploidy, is suppression or inhibition of expression of the introduced genes. Rines et al. $(2007,2008)$ reported species-specific suppression during attempts to introgress $P c$ genes into a hexaploid background. Effective crown rust resistance from A. murphyi $\mathrm{P} 12$ was suppressed in cross and backcross derivatives of A. murphyi P12 with A. sativa 'Ogle' and five other susceptible cultivars. Resistance also can be modified by the interactions of genes, acting in either a dominant or additive manner (Bush and Wise 1996; Harder and McKenzie 1984; Simons 1979). These results indicated that additional difficulties may arise and eliminate the use of some of the putative $P$. coronata resistance sources found in the study.

The use of $P$. coronata pathotypes with different IP allows us to speculate about the presence of particular $P c$ genes in the analyzed genotypes. Matching the IP of the tested accessions with the profiles identified in differential lines allows us to postulate the occurrence of known rust resistance genes in the screened genotypes. Among the genes whose presence was proposed based on the infection pattern Pc39, Pc40, Pc48, Pc55, and Pc61, all came from A. sterilis accessions collected in Israel (Leonard et al. 2004). Pc68 was derived from an A. sterilis accession from Algeria (Wong et al. 1983), Pc54 was from an A. sterilis accession from Turkey (Simons 1978), and Pc14 was derived from the Brazilian A. sativa 'Ascencao' (Gnanesh et al. 2013). Interestingly, all accessions possessing the mentioned postulated resistance genes came from Morocco, Spain, Italy, or Tunisia. Moreover, none of the tetraploids showed the infection pattern that would correspond to the presence of the genes Pc62 or Pc64, 
which were derived from $A$. sterilis accessions from Morocco, or Pc36, derived from an A. sterilis accession from Portugal (Fleischmann and McKenzie 1968; Leonard et al. 2004). Regarding the genes, whose presence in the accessions cannot be excluded because none of the isolates were virulent against them, Pc52, Pc59, Pc60, and $P c 71$ came from A. sterilis accessions collected in Israel and Pc63 came from an Algerian A. sterilis accession (Leonard et al. 2004). The differing geographical origins of the tested genotypes and the original resistance gene source allow us to speculate that the tested genotypes contain previously unidentified resistance genes. To assess the genetic background of newly identified resistance, it would be necessary to perform allelism tests.

Table 4. Crown rust (Puccinia coronata f. sp. avenae) resistance phenotypes of the wild oat accessions

\begin{tabular}{|c|c|c|c|c|c|c|c|c|c|c|}
\hline \multirow[b]{2}{*}{ Accession } & \multirow[b]{2}{*}{ Bank $^{\mathbf{b}}$} & \multirow[b]{2}{*}{ Origin } & \multicolumn{6}{|c|}{ Puccinia coronata race ${ }^{\mathrm{a}}$} & & \\
\hline & & & $\mathbf{A}$ & B & $\mathbf{C}$ & D & $\mathbf{E}$ & $\mathbf{F}$ & & {$\left[\mathbf{P}^{\mathrm{c}}\right.$} \\
\hline Amagalon $P c 91$ & NSGC & & $\mathrm{R}$ & $\mathrm{R}$ & $\mathrm{R}$ & $\mathrm{R}$ & $\mathrm{R}$ & $\mathrm{R}$ & $P c 91$ & \\
\hline \multicolumn{10}{|l|}{ Avena magna } & \\
\hline 52222 & IHAR & Unknown & $\mathrm{S}$ & $\mathrm{S}$ & $\mathrm{S}$ & MR, R & $\mathrm{S}$ & $\mathrm{S}$ & Pc54 & \\
\hline AVE 2782 & IPK & Morocco & S & $\mathrm{S}$ & S & $\mathrm{S}$ & $\mathrm{S}$ & S & & \\
\hline AVE 2783 & IPK & Morocco & $S$ & $\mathrm{~S}$ & S & $\mathrm{S}$ & $\mathrm{S}$ & $S$ & & \\
\hline AVE 2784 & IPK & Morocco & $\mathrm{S}$ & $\mathrm{S}$ & $\mathrm{S}$ & $\mathrm{S}$ & MR & $\mathrm{S}$ & Pc48, Pc55 & \\
\hline AVE 2785 & IPK & Morocco & $\mathrm{S}$ & $\mathrm{S}, \mathrm{MR}$ & $\mathrm{S}$ & $\mathrm{S}$ & $\mathrm{S}, \mathrm{R}$ & $\mathrm{S}, \mathrm{MR}$ & IP_18c & \\
\hline AVE 2795 & IPK & Morocco & $S$ & $\mathrm{~S}$ & $\mathrm{~S}$ & $\mathrm{~S}$ & $\mathrm{~S}$ & $\mathrm{~S}$ & & \\
\hline AVE 2796 & IPK & Morocco & $S$ & $\mathrm{~S}, \mathrm{R}$ & $\mathrm{S}, \mathrm{R}$ & $\mathrm{S}, \mathrm{R}$ & $\mathrm{S}$ & $\mathrm{S}, \mathrm{MR}$ & IP_17 & \\
\hline AVE 2797 & IPK & Morocco & $\mathrm{R}$ & $\mathrm{S}$ & $\mathrm{R}$ & HR & $\mathrm{R}$ & $\mathrm{S}$ & IP_14 & \\
\hline AVE 2797 & IPK & Morocco & $\mathrm{S}, \mathrm{MR}$ & $\mathrm{S}$ & $\mathrm{S}$ & $\mathrm{S}, \mathrm{MR}$ & $\mathrm{S}, \mathrm{MR}$ & $\mathrm{S}, \mathrm{MR}, \mathrm{R}$ & IP_19 & \\
\hline AVE 2797 & IPK & Morocco & $\mathrm{S}$ & MS & HR & $\mathrm{R}$ & $\mathrm{S}$ & $\mathrm{S}$ & IP_6 & \\
\hline AVE 2798 & IPK & Morocco & $S$ & $\mathrm{~S}, \mathrm{R}$ & $\mathrm{S}$ & $\mathrm{S}$ & $\mathrm{S}$ & S & IP_2 & \\
\hline AVE 2799 & IPK & Morocco & $\mathrm{S}$ & S & $\mathrm{R}$ & $\mathrm{R}$ & $\mathrm{S}$ & $\mathrm{S}$ & IP_6 & \\
\hline AVE 2847 & IPK & Unknown & $\mathrm{S}, \mathrm{MS}$ & $\mathrm{S}, \mathrm{R}, \mathrm{HR}$ & $\mathrm{S}, \mathrm{MS}, \mathrm{R}$ & $\mathrm{R}$ & S & $\mathrm{S}, \mathrm{R}$ & IP_17 & \\
\hline AVE 2849 & IPK & Morocco & $\mathrm{S}$ & $\mathrm{S}$ & $\mathrm{S}$ & $\mathrm{S}$ & $\mathrm{S}$ & S & & \\
\hline AVE 2850 & IPK & Unknown & $\mathrm{S}$ & $\mathrm{S}$ & S & $\mathrm{S}$ & S & $\mathrm{S}$ & & \\
\hline AVE 2852 & IPK & Morocco & S, MR & $\mathrm{S}, \mathrm{MR}$ & S & $\mathrm{S}, \mathrm{MR}$ & S & MR, $R$ & IP_16 & \\
\hline AVE 4709 & IPK & Unknown & $\mathrm{S}$ & $\mathrm{S}$ & S & S & S & S & & \\
\hline Cc 7069 & IBERS & Morocco & $S$ & $\mathrm{~S}$ & S & $\mathrm{R}$ & $\mathrm{S}$ & S & Pc54 & \\
\hline Cc 7070 & IBERS & Morocco & $\mathrm{S}$ & $\mathrm{S}$ & $S$ & S & $\mathrm{S}$ & $\mathrm{S}$ & & - \\
\hline Cc 7073 & IBERS & Morocco & $\mathrm{S}, \mathrm{HR}$ & $\mathrm{S}, \mathrm{MR}$ & S & $\mathrm{S}$ & $\mathrm{S}$ & $\mathrm{R}$ & IP_15 & \\
\hline $\mathrm{Cc} 7183 \mathrm{~A}$ & IBERS & Spain & $\mathrm{S}$ & $\mathrm{S}, \mathrm{R}$ & $\mathrm{S}$ & S & $\mathrm{S}$ & $\mathrm{S}, \mathrm{MR}$ & Pc39 & \\
\hline Cc 7183B & IBERS & Spain & $\mathrm{S}, \mathrm{R}$ & MR & $\mathrm{S}, \mathrm{HR}$ & MR, R & $\mathrm{S}$ & S & IP_8 & \\
\hline Cc 7186 & IBERS & Spain & $\mathrm{S}$ & $\mathrm{S}$ & $\mathrm{S}$ & $\mathrm{S}, \mathrm{R}$ & $\mathrm{S}, \mathrm{R}$ & S & IP_11 & \\
\hline Cc 7237 & IBERS & Morocco & MR & MR & MS & $\mathrm{R}$ & $\mathrm{R}$ & MR & Pc50 & \\
\hline Cc 7239 & IBERS & Morocco & $\mathrm{S}$ & MR & HR & $\mathrm{R}$ & S & S & IP_7 & \\
\hline Cc 7241 & IBERS & Morocco & S, MR & $\mathrm{S}, \mathrm{MR}, \mathrm{HR}$ & $\mathrm{S}, \mathrm{R}, \mathrm{HR}$ & MR, HR & $\mathrm{S}$ & MR, S & Pc68 & \\
\hline Cc 7245 & IBERS & Morocco & $\mathrm{S}$ & $\mathrm{S}$ & $\mathrm{S}$ & $\mathrm{S}$ & $\mathrm{S}$ & $\mathrm{S}$ & & - \\
\hline Cc 7246 & IBERS & Morocco & $S$ & $\mathrm{~S}$ & S & $S$ & $\mathrm{~S}$ & S & & - \\
\hline Cc 7248 & IBERS & Morocco & $S$ & $\mathrm{~S}$ & S & S & $\mathrm{S}$ & S & & - \\
\hline CIav 8331 & PGRC & Morocco & $\mathrm{S}$ & $\mathrm{S}, \mathrm{MR}$ & $\mathrm{S}$ & MR & $\mathrm{S}, \mathrm{R}$ & $S$ & IP_12 & \\
\hline CIav 8330 & PGRC & Morocco & S, MR & $\mathrm{S}, \mathrm{MS}, \mathrm{R}$ & $\mathrm{S}, \mathrm{MR}$ & $\mathrm{S}$ & S, MR & S & IP_10 & \\
\hline CN 23040 & PGRC & Morocco & $\mathrm{S}$ & $\mathrm{S}$ & $\mathrm{S}$ & $\mathrm{R}$ & MS & S & Pc54 & \\
\hline CN 23043 & PGRC & Morocco & S & $\mathrm{S}$ & $S$ & $\mathrm{~S}, \mathrm{R}$ & $\mathrm{S}$ & S & Pc54 & \\
\hline CN 23044 & PGRC & Morocco & S & MS & $S$ & $\mathrm{R}$ & $\mathrm{S}$ & S & Pc54 & \\
\hline CN 23049 & PGRC & Morocco & S & $\mathrm{S}$ & S & $\mathrm{S}$ & $\mathrm{S}$ & S & & - \\
\hline CN 23050 & PGRC & Morocco & S & $\mathrm{S}$ & $\mathrm{S}$ & $\mathrm{S}$ & $\mathrm{S}$ & S & & - \\
\hline CN 23051 & PGRC & Morocco & S & $\mathrm{R}$ & HR & HR & MS & S & IP_7 & \\
\hline CN 23057 & PGRC & Morocco & S & $\mathrm{S}$ & $\mathrm{S}$ & $\mathrm{S}$ & $\mathrm{S}$ & $S$ & & - \\
\hline CN 23058 & PGRC & Morocco & S & $\mathrm{S}$ & S & $\mathrm{S}$ & $\mathrm{S}$ & S & & - \\
\hline CN 23059 & PGRC & Morocco & S & S & $S$ & $\mathrm{~S}$ & $\mathrm{~S}$ & S & & - \\
\hline CN 23060 & PGRC & Morocco & S & $\mathrm{S}$ & S & $\mathrm{S}$ & $\mathrm{S}$ & S & & - \\
\hline CN 23062 & PGRC & Morocco & S & $\mathrm{S}$ & S & $\mathrm{S}$ & $\mathrm{S}$ & S & & - \\
\hline CN 23085 & PGRC & Morocco & $S$ & $\mathrm{~S}$ & S & $\mathrm{S}$ & $\mathrm{S}$ & S & & - \\
\hline CN 23114 & PGRC & Morocco & S & $\mathrm{S}$ & S & $\mathrm{S}, \mathrm{R}$ & $\mathrm{S}$ & S & Pc54 & \\
\hline CN 23210 & PGRC & Morocco & S & S & S & $\mathrm{S}$ & S & S & & - \\
\hline
\end{tabular}

${ }^{a}$ Resistance phenotype: $\mathrm{S}=$ susceptible, large to moderately large pustules with little or no chlorosis; MS = moderately susceptible, moderately large pustules surrounded by extensive chlorosis; $\mathrm{MR}=$ moderately resistant, small pustule surrounded by chlorosis; $\mathrm{R}=$ resistant, chlorotic or necrotic flecking; and HR = highly resistant, no visible reaction.

b Gene banks: BYU = Department of Plant and Wildlife Sciences, Brigham Young University, Provo, UT; IBERS = Genetic Resources Unit, Institute of Biological, Environmental and Rural Sciences, Aberystwyth, Wales; IHAR = National Centre For Plant Genetic Resources, The Plant Breeding and Acclimatization Institute, NRI, Radzików, Poland; IPK = Leibniz Institute of Plant Genetics and Crop Plant Research, Gatersleben, Germany; NSGC = National Small Grains Collection, Aberdeen, ID; PGRC = Plant Gene Resources of Canada, Agriculture and Agri-Food Canada, Saskatoon, Canada; and VIR = N. I. Vavilov Institute of Plant Genetic Resources, St. Petersburg, Russia.

c Postulated $P c$ genes infection profile (IP): infection pattern determined for six tested isolates.

d Undefined hexaploid species.

e Verified hexaploid A. sterilis obtained as A. magna. 
Another postulated gene is $P c 91$, which was obtained from the CI 8330 accession of A. magna collected in 1964 in Morocco in the area of Khemisset, $30 \mathrm{~km}$ south of Tiflet $\left(33^{\circ} 42^{\prime} \mathrm{N}, 6^{\circ} 19^{\prime} \mathrm{W}\right)$. The presence of the $P c 91$ gene in the most resistant of the analyzed accessions would be very likely due to their Moroccan origin. However, both resistant genotypes of A. murphyi, Cc 7190 and PI 657600, were collected in the Tangier area, the former in $1985\left(35^{\circ} 50^{\prime} \mathrm{N}, 5^{\circ} 50^{\prime} \mathrm{W}\right)$ and the latter in $1987\left(35^{\circ} 41^{\prime} \mathrm{N}, 5^{\circ} 49^{\prime} \mathrm{W}\right)$. Both locations are separated from Khemisset by a geographical barrier in the form of the Rif
Mountains, constituting the northernmost part of the Atlas mountain range. PI 657615, PI 657616, and PI 657618, originally thought to be A. magna, were also collected in Morocco in 1987. The first two accessions were collected in the Merchouch area $\left(33^{\circ} 30^{\prime} \mathrm{N}, 6^{\circ} 43^{\prime} \mathrm{W}\right)$ and the last one in Rommani $\left(33^{\circ} 32^{\prime} \mathrm{N}, 6^{\circ} 36^{\prime} \mathrm{N}\right)$. Both locations are approximately 80 to $90 \mathrm{~km}$ west of the CI 8330 sampling site and are also separated from Khemisset by many geographical barriers, such as hills and river valleys, which indicates that these accessions likely contain a gene or genes other than Pc91. Nevertheless, it would be

Table 4. (continued from preceding page)

\begin{tabular}{|c|c|c|c|c|c|c|c|c|c|}
\hline \multirow[b]{2}{*}{ Accession } & \multirow[b]{2}{*}{ Bank $^{\mathbf{b}}$} & \multirow[b]{2}{*}{ Origin } & \multicolumn{6}{|c|}{ Puccinia coronata race $^{\mathrm{a}}$} & \multirow[b]{2}{*}{$\mathbf{I P}^{\mathbf{c}}$} \\
\hline & & & $\mathbf{A}$ & B & $\mathbf{C}$ & D & $\mathbf{E}$ & $\mathbf{F}$ & \\
\hline CN 23211 & PGRC & Morocco & $S$ & $S$ & $S$ & $\mathrm{~S}$ & $\mathrm{~S}$ & $S$ & - \\
\hline CN 23214 & PGRC & Morocco & S & S & $S$ & S & $\mathrm{S}$ & S & - \\
\hline CN 23220 & PGRC & Morocco & S & S & S & S & $\mathrm{S}$ & S & - \\
\hline CN 23224 & PGRC & Morocco & S & S & S & S & $\mathrm{S}$ & S & - \\
\hline CN 23520 & PGRC & Morocco & $S$ & $S$ & S & $S$ & S & S & - \\
\hline CN 39255 & PGRC & Morocco & S & S & S & S & $\mathrm{S}$ & S & - \\
\hline CN 48711 & PGRC & Unknown & S & S & S & $\mathrm{S}$ & $\mathrm{S}$ & S & - \\
\hline PI 657288 & NSGC & Morocco & S & S & S & $\mathrm{S}$ & S & S & - \\
\hline VIR 172 & VIR & Morocco & S & S & S & $\mathrm{S}$ & S & S & - \\
\hline VIR 1786 & VIR & Morocco & $S$ & $\mathrm{R}$ & $\mathrm{R}$ & $\mathrm{R}$ & MS & S & IP_7 \\
\hline VIR 1787 & VIR & Morocco & S & $\mathrm{S}, \mathrm{R}$ & $\mathrm{S}, \mathrm{HR}$ & $\mathrm{S}, \mathrm{MR}$ & $\mathrm{S}$ & S & IP_7 \\
\hline VIR 1896 & VIR & Morocco & S & S & $\mathrm{S}$ & S & $\mathrm{S}$ & S & - \\
\hline VIR 2099 & VIR & Morocco & S & $\mathrm{S}, \mathrm{HR}$ & $\mathrm{S}, \mathrm{MR}$ & $\mathrm{R}, \mathrm{HR}$ & $\mathrm{S}$ & S & IP_7 \\
\hline VIR 2100 & VIR & Morocco & $S$ & $\mathrm{R}$ & HR & $\mathrm{HR}$ & $\mathrm{S}$ & S & IP_7 \\
\hline \multicolumn{10}{|l|}{ A. murphyi } \\
\hline 52220 & IHAR & Unknown & $\mathrm{S}$ & $\mathrm{S}$ & MR, R & $\mathrm{S}$ & $\mathrm{S}, \mathrm{R}$ & S & Pc67 \\
\hline AVE 2800 & IPK & Unknown & $\mathrm{S}, \mathrm{R}$ & $\mathrm{S}, \mathrm{MR}$ & $\mathrm{S}$ & $\mathrm{S}, \mathrm{MR}$ & $\mathrm{S}$ & S & IP_5 \\
\hline AVE 2811 & IPK & Unknown & $\mathrm{R}$ & $\mathrm{S}$ & $S$ & S & $\mathrm{S}$ & S & IP_1 \\
\hline AVE 2846 & IPK & Spain & S & $\mathrm{S}$ & S & S & $\mathrm{S}$ & $\mathrm{S}$ & - \\
\hline Cc 7178 & IBERS & Spain & S & $\mathrm{S}, \mathrm{MR}$ & MR, R & $\mathrm{S}, \mathrm{MR}$ & $\mathrm{S}, \mathrm{R}$ & $\mathrm{S}, \mathrm{R}$ & Pc61 \\
\hline Cc 7179 & IBERS & Spain & S & $\mathrm{S}$ & MR, R & $\mathrm{S}$ & $\mathrm{S}$ & $\mathrm{S}, \mathrm{R}$ & Pc40 \\
\hline Cc 7180 & IBERS & $\begin{array}{l}\text { Spain/Canary } \\
\text { Islands }\end{array}$ & $S$ & MS & $\mathrm{HR}$ & $\mathrm{R}$ & HR & $\mathrm{R}$ & Pc14, Pc97, Pc101 \\
\hline Cc 7181 & IBERS & Spain & MR, R & $\mathrm{S}, \mathrm{R}$ & $S$ & $\mathrm{~S}, \mathrm{MR}$ & $\mathrm{S}, \mathrm{MR}$ & $\mathrm{S}, \mathrm{R}$ & Pc50 \\
\hline Cc 7182 & IBERS & Spain & $\mathrm{S}$ & $\mathrm{S}$ & $\mathrm{S}$ & $\mathrm{S}$ & $\mathrm{S}$ & S & - \\
\hline Cc 7184 & IBERS & Spain & $\mathrm{S}, \mathrm{MR}$ & $\mathrm{S}$ & $\mathrm{S}, \mathrm{R}$ & S & $\mathrm{S}$ & S & IP_3 \\
\hline Cc 7185 & IBERS & Spain & $\mathrm{S}, \mathrm{MR}$ & $\mathrm{S}$ & $\mathrm{S}, \mathrm{R}, \mathrm{HR}$ & $\mathrm{R}$ & $\mathrm{R}$ & $\mathrm{S}, \mathrm{R}$ & Pc104 \\
\hline Cc 7187 & IBERS & Spain & $\mathrm{S}$ & $\mathrm{S}$ & $\mathrm{S}$ & $\mathrm{S}$ & $\mathrm{S}$ & $\mathrm{S}$ & - \\
\hline Cc 7188 & IBERS & Morocco & $\mathrm{S}$ & $\mathrm{S}, \mathrm{HR}$ & MR, HR & $\mathrm{S}, \mathrm{HR}$ & $\mathrm{S}$ & MR, R, HR & IP_17 \\
\hline Cc 7189 & IBERS & Morocco & MR, R & MR, R & $\mathrm{R}$ & $\mathrm{R}, \mathrm{HR}$ & $\mathrm{S}$ & $\mathrm{S}$ & IP_8 \\
\hline Cc 7190 & IBERS & Morocco & $\mathrm{S}, \mathrm{R}$ & $\mathrm{S}, \mathrm{MR}$ & $\mathrm{S}, \mathrm{MR}$ & $\mathrm{S}, \mathrm{MR}, \mathrm{HR}$ & $\mathrm{S}, \mathrm{MR}$ & $\mathrm{S}, \mathrm{MR}, \mathrm{R}$ & $\begin{array}{l}\text { Pc52, Pc59, Pc60, Рc63, } \\
\text { Pc71,Pc91 }\end{array}$ \\
\hline Cc 7240 & IBERS & Morocco & $\mathrm{S}$ & $\mathrm{S}$ & $\mathrm{R}$ & $\mathrm{R}, \mathrm{HR}$ & $\mathrm{R}$ & $\mathrm{R}$ & Pc14, Pc97, Pc101 \\
\hline CN 21989 & PGRC & Spain & $S, R$ & $\mathrm{~S}, \mathrm{MR}$ & $\mathrm{S}$ & $\mathrm{S}$ & $\mathrm{S}, \mathrm{MR}$ & S & IP_9 \\
\hline PI 657600 & NSGC & Morocco & $\mathrm{S}, \mathrm{MR}$ & $\mathrm{S}, \mathrm{MR}, \mathrm{HR}$ & HR & $\mathrm{R}, \mathrm{HR}$ & HR & $\mathrm{S}, \mathrm{R}$ & $\begin{array}{l}\text { Pc52, Pc59, Pc60, Рc63, } \\
\text { Pc71,Pc91 }\end{array}$ \\
\hline PI 657606 & NSGC & Morocco & $\mathrm{R}$ & $\mathrm{S}$ & $\mathrm{S}$ & $\mathrm{R}$ & MS & S & IP_4 \\
\hline VIR 1986 & VIR & Spain & S & $\mathrm{S}$ & MS & MS & $\mathrm{S}$ & S & - \\
\hline VIR 2088 & VIR & Spain & S & $\mathrm{S}$ & $\mathrm{S}$ & $\mathrm{S}$ & S & S & - \\
\hline VIR 2101 & VIR & Spain & MR & MS & S & $\mathrm{S}$ & S & S & IP_1 \\
\hline \multicolumn{10}{|l|}{ A. insularis } \\
\hline 2067 VIR & VIR & Italy & S & S & $S$ & $\mathrm{R}, \mathrm{S}$ & $\mathrm{S}$ & $S$ & Pc54 \\
\hline 2102 TMP 2007 & VIR & Italy & S & $\mathrm{S}$ & S & $\mathrm{S}$ & S & S & - \\
\hline BYU 207 & BYU & Italy & $\mathrm{S}$ & $\mathrm{S}$ & $\mathrm{S}$ & $\mathrm{S}$ & $\mathrm{S}$ & S & - \\
\hline CN 108634 & PGRC & Tunisia & S & $\mathrm{S}$ & S & $\mathrm{S}$ & $\mathrm{S}$ & S & - \\
\hline \multicolumn{10}{|l|}{ Undefined $^{\mathrm{d}}$} \\
\hline Cc 7243 & IBERS & Morocco & $\mathrm{S}, \mathrm{MR}$ & $\mathrm{S}, \mathrm{MR}$ & $S$ & $\mathrm{~S}, \mathrm{R}$ & $\mathrm{S}, \mathrm{MR}$ & $\mathrm{S}$ & IP_13 \\
\hline Cc 7244 & IBERS & Morocco & $\mathrm{S}$ & $\mathrm{S}$ & $\mathrm{S}$ & $\mathrm{S}$ & $\mathrm{S}$ & $\mathrm{S}$ & - \\
\hline Cc 7247 & IBERS & Morocco & S & $\mathrm{S}$ & $\mathrm{HR}$ & $\mathrm{R}$ & $\mathrm{R}$ & $\mathrm{R}$ & Pc14, Pc97, Pc101 \\
\hline PI 657615 & NSGC & Morocco & MR & HR & $\mathrm{R}$ & $\mathrm{R}$ & $\mathrm{R}$ & $\mathrm{R}$ & $\begin{array}{l}\text { Pc52, Pc59, Pc60, Рc63, } \\
\text { Pc71,Pc91 }\end{array}$ \\
\hline PI 657616 & NSGC & Morocco & $\mathrm{R}$ & MR & $\mathrm{R}$ & $\mathrm{R}$ & $\mathrm{R}$ & $\mathrm{R}$ & $\begin{array}{l}\text { Pc52, Pc59, Pc60, Pc63, } \\
\quad \text { Pc71, Pc91 }\end{array}$ \\
\hline PI 657618 & NSGC & Morocco & $\mathrm{R}$ & $\mathrm{R}, \mathrm{HR}$ & $\mathrm{R}$ & $\mathrm{R}$ & $\mathrm{S}, \mathrm{R}$ & $\mathrm{R}$ & $\begin{array}{l}\text { Pc52, Pc59, Pc60, Рc63, } \\
\text { Pc71, Pc91 }\end{array}$ \\
\hline \multicolumn{10}{|l|}{ Hexaploide } \\
\hline PI 657271 & NSGC & Morocco & $\mathrm{S}$ & MR & $\mathrm{S}$ & $\mathrm{S}$ & $S$ & $S$ & IP_2 \\
\hline
\end{tabular}


recommended to use $P$. coronata isolates virulent against $P c 52$, $P c 59, P c 60, P c 63, P c 71$, and $P c 91$ to verify whether the identified resistance is conditioned by known $P c$ genes instead of any new ones.

Current sources of resistance to crown rust rapidly lose their effectiveness due to shifts in pathogen virulence; therefore, recent efforts have focused on identifying new $P c$ genes. The broad spectrum of potentially novel resistance genes within A. magna and A. murphyi genotypes revealed in this article may be useful; however, one cannot expect that introgression of the genes into hexaploid oat will be successful and straightforward. Moreover, it will be necessary to determine whether each form of resistance identified in the analyzed tetraploids is conditioned by a single gene or a combination of different genes. To check monogenic inheritance, resistant accessions should be crossed with susceptible ones of the same species to minimize the effects of chromosomal aberrations resulting from interspecific crosses.

A promising alternative to using the tetraploids would be taking advantage of the extremely effective resistance in the accessions whose ploidy level was verified as being hexaploid. Hexaploid accessions PI 657615, PI 657616, and PI 657618 should readily hybridize with cultivated oat accessions, thereby enabling the effective use of their $P c$ genes. The results obtained encourage the investigation of the genetic basis of resistance in seedlings, as well as at the adult plant stage. It should be noted that, although race-specific resistance is effective, it can easily be overcome by the fast evolution of the pathogen. Breeding based on the pyramidization of $P c$ genes with different (strong or weak) effects might significantly increase the durability of resistance in oat. Genes providing partial resistance that have been identified in this work can also be valuable in this context.

\section{Acknowledgments}

This research was supported by the Ministry of Agriculture and Rural Development of the Republic of Poland Grant 2014-2020: "Crown rust resistance genes pyramiding in oat genome and identification of DNA markers for these genes". We thank M. Carson and G. Ochocki (United States Department of Agriculture-Agricultural Research Service, Cereal Disease Laboratory, St. Paul, MN), J. Mitchell Fetch (Agriculture and Agri-Food Canada, Brandon Research Centre, Brandon, MB, Canada), and J. Menzies (Agriculture and AgriFood Canada, Morden, MB, Canada) for providing oat reference lines with $P c$ resistance genes; E. Śliwińska (Laboratory of Molecular Biology and Cytometry, University of Technology and Life Sciences, Bydgoszcz, Poland) for ploidy level analysis; and E. N. Jellen (Department of Plant and Wildlife Sciences, Brigham Young University, Provo, UT) for providing A. insularis (BYU 207) seeds.

\section{Literature Cited}

Aung, T., Chong, J., and Leggett, M. 1996. The transfer of crown rust resistance Pc94 from a wild diploid to cultivated hexaploid oat. Pages 167-171 in: 9th Int. Eur. Mediterr. Cereal Rust Powdery Mildews Conf. G. H. J. Kema, R. E. Niks, and R. A. Daamen, eds. Wageningen, European and Mediterranean Cereal Rust Foundation, Lunteren, The Netherlands.

Budzyński, W., and Szempliński, W. 2003. Owies. Pages 239-258 in: Szczegółowa uprawa roślin. Z. Jasińska and W. Kotecki, eds. Agricultural Academy, Wrocław, Poland.

Bush, A. L., and Wise, R. P. 1996. Crown rust resistance loci on linkage groups 4 and 13 in cultivated oat. J. Hered. 87:427-432.

Cabral, A. L., and Park, R. F. 2014. Seedling resistance to Puccinia coronata f. sp. avenae in Avena strigosa, A. barbata and A. sativa. Euphytica 196: 385-395.

Cabral, A. L., Singh, D., and Park, R. F. 2011. Identification and genetic characterisation of adult plant resistance to crown rust in diploid and tetraploid accessions of Avena. Ann. Appl. Biol. 159:220-228.

Carson, M. L. 2009a. Broad-spectrum resistance to crown rust, Puccinia coronata f. sp. avenae, in accessions of the tetraploid slender oat, Avena barbata. Plant Dis. 93:363-366.

Carson, M. L. 2009b. Cereal Disease Laboratory: Oat crown rust race survey results-2008. Online publication. http://www.ars.usda.gov/Main/docs.htm? docid $=10493$

Carson, M. L. 2010. Additional sources of broad-spectrum resistance to Puccinia coronata f. sp. avenae from Canadian accessions of Avena barbata. Plant Dis. 94:1405-1410.

Carson, M. L. 2011. Virulence in oat crown rust (Puccinia coronata f. sp. avenae) in the United States from 2006 through 2009. Plant Dis. 95:1528-1534.
Chong, J., Gruenke, J., Dueck, R., Mayert, W., Mitchell Fetch, J. W., and McCartney, C. A. 2011. Virulence of Puccinia coronata f. sp. avenae in the eastern prairie region of Canada during 2007-2009. Can. J. Plant Pathol. 33: 77-87.

Chong, J., Gruenke, J., Dueck, R., Mayert, W., and Woods, S. 2008. Virulence of oat crown rust Puccinia coronata f. sp. avenae in Canada during 2002-2006. Can. J. Plant Pathol. 30:115-123.

Chong, J., Leonard, K. J., and Salmeron, J. J. 2000. A North American system of nomenclature for Puccinia coronata f. sp. avenae. Plant Dis. 84: 580-585.

Dyck, P. L., and Zillinsky, F. J. 1963. Inheritance of crown rust resistance transferred from diploid to hexaploid oats. Can. J. Genet. Cytol. 5:398-407.

Fleischmann, G., and McKenzie, R. I. H. 1968. Inheritance of crown rust resistance in Avena sterilis. Crop Sci. 8:710-713.

Galbraith, D. W., Harkins, K. R., Maddox, J. M., Ayres, N. M., Sharma, D. P., and Firoozabady, E. 1983. Rapid flow cytometric analysis of the cell cycle in intact plant tissues. Science 220:1049-1051.

Gnanesh, B. N., Fetch, J. M., Zegeye, T., McCartney, C. A., and Fetch, T. 2013. Oat. Pages 51-73 in: Alien Gene Transfer in Crop Plants. A. Pratap and J. Kumar, eds. Springer, New York, Heidelberg, Dordrecht, London.

Harder, D. E., and Haber, S. 1992. Oat diseases and pathological techniques. Pages 307-425 in: Oat Science and Technology, Agronomy Monograph No. 33. H. G. Marshall and M. E. Sorrells, eds. American Society of Agronomy, Crop Science Society of America, Madison, WI.

Harder, D. E., and McKenzie, R. I. H. 1980. Inheritance of crown rust resistance in three accessions of Avena sterilis. Can. J. Genet. Cytol. 22:27-33.

Harder, D. E., and McKenzie, R. I. H. 1984. Complex additive type of resistance to Puccinia coronata in Avena sterilis. Can. J. Plant Pathol. 6:135-138.

Harlan, J. R., and de Wet, J. M. J. 1971. Toward a rational classification of cultivated plants. Taxon 20:509-517.

Hsam, S. L. K., Peters, N., Paderina, E. V., Felsenstein, F., Oppitz, K., and Zeller, F. J. 1997. Genetic studies of powdery mildew resistance in common oat (Avena sativa L.) I. Cultivars and breeding lines grown in Western Europe and North America. Euphytica 96:421-427.

Jellen, E., and Leggett, J. M. 2006. Cytogenetic manipulation in oat improvement. Pages 199-231 in: Genetic Resources, Chromosome Engineering, and Crop Improvement, Vol. 2 Cereals. R. J. Singh and P. P. Jauhar, eds. CRC Taylor \& Francis Press, Boca Raton, FL.

Karow, R. S., McNamara, K. R., and Forsberg, R. A. 1987. Crown rust resistance in progeny from a derived tetraploid $\times$ natural tetraploid cross in Avena. Genome 29:206-208.

Kiehn, F. A., McKenzie, R. I. H., and Harder, D. E. 1976. Inheritance of resistance to Puccinia coronata avenae and its association with seed characteristics in four accessions of Avena sterilis. Can. J. Genet. Cytol. 18:717-726.

Ladizinsky, G. 1988. Biological species and wild genetic resources in Avena. Pages 76-86 in: 3rd Int. Oat Conf. Lund, Sweden.

Leonard, K. J., Anikster, Y., and Manisterski, J. 2004. Patterns of virulence in natural populations of Puccinia coronata on wild oat in Israel and in agricultural populations on cultivated oat in the United States. Phytopathology 94:505-514.

Loskutov, I. G., and Rines, H. W. 2011. Avena. Pages 109-183 in: Wild Crop Relatives: Genomic and Breeding Resources. C. Kole, ed. Springer, Berlin, Heidelberg.

Martens, J. W., and Dyck, P. L. 1989. Genetics of resistance to rust in cereals from a Canadian perspective. Can. J. Plant Pathol. 11:78-85.

Martens, J. W., Fleischmann, G., and McKenzie, R. I. H. 1972. Effects of natural infections of crown rust and stem rust on yield and quality of oats in Manitoba. Can. Plant Dis. Surv. 52:122-125.

Martens, J. W., McKenzie, R. I. H., and Harder, D. E. 1980. Resistance to Puccinia graminis avenae and $P$. coronate avenae in the wild and cultivated Avena populations of Iran, Iraq, and Turkey. Can. J. Genet. Cytol. 22:641-649.

McCartney, C. A., Stonehouse, R. G., Rossnagel, B. G., Eckstein, P. E., Scoles, G. J., Zatorski, T., Beattie, A. D., and Chong, J. 2011. Mapping of the oat crown rust resistance gene $P c 91$. Theor. Appl. Genet. 122:317-325.

McMullen, M. S., Doehlert, D. C., and Miller, J. D. 2005. Registration of "HiFi". Oat. Crop Sci. 45:1664

Menzies, J. G., Xue, A., Dueck, R., and Greunke, J. 2015. Virulence of Puccinia coronata f. sp. avenae. Page 95 in: 14th Int. Cereal Rust Powdery Mildew Conf. Copenhagen.

Mitchell Fetch, J. W., Duguid, S. D., Brown, P. D., Chong, J., Fetch, T. G., Haber, S. M., Menzies, J. G., Ames, N., Noll, J., Aung, T., and Stadnyk, K. D. 2007. Leggett oat. Can. J. Plant Sci. 87:509-512.

Mitchell Fetch, J. W., Tekauz, A., Brown, P. D., Ames, N., Chong, J., Fetch, T. G., Jr., Haber, S. M., Menzies, J. G., Townley-Smith, T. F., Stadnyk, K. D., and Green, D. A. 2013. Stride oat. Can. J. Plant Sci. 93:749-753.

Murphy, H. C. 1935. Physiologic specialisation in Puccinia coronata f. sp. avenae. Bull. U.S. Dep. Agric. 433:1-48.

Park, R. 2013. New oat crown rust pathotype with virulence for $P c 91$. Cereal Rust Rep. 11:8-10.

Rines, H. W., Porter, H. L., and Carson, M. L. 2008. Suppressors of oat crown rust resistance in interspecific oat crosses. Poster V-7 in: 8th Int. Oat Conf. Minneapolis, $\mathrm{MN}$.

Rines, H. W., Porter, H. L., Carson, M. L., and Ochocki, G. E. 2007. Introgression of crown rust resistance from diploid oat Avena strigosa into hexaploid 
cultivated oat $A$. sativa by two methods: Direct crosses and through an initial 2x:4x synthetic hexaploid. Euphytica 158:67-79.

Rooney, W. L., Rines, H. W., and Phillips, R. L. 1994. Identification of RFLP markers linked to crown rust resistance genes $P c 91$ and $P c 92$ in oat. Crop Sci. 34:940-944.

Rothman, P. G. 1984. Registration of four stem rust and crown rust resistant oat germplasm lines. Crop Sci. 24:1217.

Sadanaga, K., and Simon, M. D. 1960. Transfer of crown rust resistance of diploid and tetraploid species to hexaploid oats. Agron. J. 52:285-288.

Segal, A., Manisterski, J., Fishbeck, G., and Wahl, I. 1980. How plant populations defend themselves in natural ecosystem. Pages 75-102 in: Plant Disease: An Advanced Treatise. J. G. Horsfall and E. B. Cowling, eds. Academic Press, New York.

Simons, M. D., Martens, J. W., McKenzie, R. I. H., Nishiyama, I., Sadanaga, K., Sebesta, J., and Thomas, H. 1978. Oats: A standardized system of nomenclature for genes and chromosomes and catalog of genes governing characters. U.S. Department of Agriculture, Science and Education Administration, Washington, DC.
Simons, M. D. 1979. Influence of genes for resistance to Puccinia coronata from Avena sterilis on yield and rust reaction of cultivated oats. Phytopathology 69: 450-452.

Simons, M. D. 1985. Crown rust. Pages 131-172 in: The Cereal Rust, Vol. 2: Diseases, Distribution, Epidemiology, and Control. A. P. Roelfs and W. R. Bushnel, eds. Academic Press, Orlando, FL.

Simons, M. D., Rothman, P. G., and Michel, L. J. 1979. Pathogenicity of Puccinia coronata from buckthorn and from oats adjacent to and distant from buckthorn. Phytopathology 69:156-158.

Tan, M. Y. A., and Carson, M. L. 2013. Screening wild oat accessions from Morocco for resistance to Puccinia coronata. Plant Dis. 97:1544-1548.

Wise, R. P., Lee, M., and Rayapati, P. J. 1996. Recombination within a 5 cM region in diploid Avena reveals multiple specificities conferring resistance to Puccinia coronata. Phytopathology 86:340-346.

Wong, L. S. L., McKenzie, R. I. H., Harder, D. E., and Martens, J. W. 1983. The inheritance of resistance to Puccinia coronata and of floret characters in Avena sterilis. Can. J. Genet. Cytol. 25:329-335. 